Staphylococcus spp. em leite humano utilizado em UTI. Camargo, Firmo e Reiter.

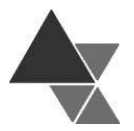

SEGURANCA

alimentar e nutricional

\title{
Incidência de Staphylococcus spp. em leite humano porcionado em lactário para utilização em UTI
}

\author{
Anice Milbratz de Camargo ${ }^{1}$, Cláudia Rafaela Marques Firmo ${ }^{1}$, Mercedes Gabriela Ratto
}

\section{Reiter $^{2}$}

Foi pesquisado Staphylococcus spp. em leite humano $(\mathrm{LH})$ pasteurizado, proveniente de Banco de Leite Humano $(\mathrm{BLH})$ e porcionado em lactário de um Hospital público em Santa Catarina (Brasil). A coleta das amostras foi realizada aleatoriamente no período de 2013/2014 pelos próprios profissionais do lactário quando do porcionamento do leite para utilização em UTI, armazenando-as em eppendorfs estéreis. A análise microbiológica seguiu as normas internacionais da APHA (2015). Encontraram-se 36\% ( $\mathrm{n}=18$ do total de $\mathrm{n}=50)$ das amostras com presença de Staphylococcus spp., sendo todas ( $\mathrm{n}=18)$ Gram e catalase positivas e coagulase negativa $(\mathrm{SCoN})$. Destas 18 amostras, 38,8\% (n=7) ultrapassaram os limites permitidos pela legislação nacional ( $14 \%$ do $\mathrm{n}$ total), não devendo ser utilizadas por se tratar de bactéria patogênica e estes valores referirem-se a contagem total. Os valores encontrados foram significativos e associam-se a grandes riscos de morbi-mortalidade. É necessária a adoção das boas práticas higiênico-sanitárias na manipulação do LH no lactário estudado, pois esta feita de forma inadequada mostrou-se um fator significativo de transmissão bacteriana. Além disso, é necessária a revisão da metodologia de controle microbiológico local, para torná-lo mais rígido no serviço de manipulação, buscando reduzir significativamente a incidência de contaminação do LH fornecido em condições adequadas pelos BLH.

Palavras-chave: Doenças transmitidas por alimentos, Saúde pública, Microbiologia de alimentos.

\section{Incidence of Staphylococcus spp. in human milk portioned in milk dispensary for utilization in ICU}

This study surveyed Staphylococcus spp. in pasteurized human milk (HM), coming from Human Milk Bank (HMB) and portioned in a Hospital milk dispensary in the brazilian state of Santa Catarina. The sample collection randomly occurred between 2013 and 2014 and was carried out by the milk dispensary's own professionals at the time of portioning, using sterile Eppendorf tubes for storage. Microbiological analysis followed APHA (2015) international standards. It was found that 36\% ( $\mathrm{n}=18$ from a total of $\mathrm{n}=50$ ) of the samples contained Staphylococcus spp., being all $(\mathrm{n}=18)$ Gram and catalase tests positives and coagulase negatives (CoNS). From these 18 samples, 38.8\% ( $\mathrm{n}=7$ ) exceeded the limits permitted by national law (14\% of total $n$ ) and should be discarted because of the pathogenic nature of these bacteria, considering that these values refer to the total count. The values were significant and are associated with high risk of morbi-mortality. The adoption of good hygienicsanitary practices in HM handling in the studied milk dispensary is necessary, because the result of this improperly made is significant bacterial transmission factor. Additionally, a review of the local microbiological control is needed to make it more rigid in handling service. This would greatly reduce the incidence of contamination in HM provided in appropriate conditions by the HMB.

Key-words: Foodborne diseases, Public health, Food microbiology.

\footnotetext{
${ }^{1}$ Universidade Regional de Blumenau. Departamento de Ciências Farmacêuticas. Curso de Nutrição. E-mail: markes.nutri@gmail.com; anice.camargo@gmail.com

2 Professora Doutora-Universidade Regional de Blumenau. Departamento de Ciências Naturais. Laboratório de Microbiologia. Rua São Paulo, 2171. Campus III - Itoupava Seca. CEP: 89030-000 - Blumenau - SC. E-mail: meme.gabriela@me.com 


\section{INTRODUÇÃO}

O gênero Staphylococcus faz parte de uma subdivisão filogenética de bactérias do tipo Gram e catalase positivas que tem como hospedeiros normais o ser humano e os animais, habitando nestes, principalmente, a pele e mucosas. As bactérias deste gênero podem ocasionalmente acarretar infecções sérias, como: furúnculos, pneumonia, osteomielite, meningite, artrite e outras patologias. Atualmente as cepas de Staphylococcus spp. constituem coletivamente a causa mais comum de septicemias hospitalares, sendo as infecções frequentemente iniciadas em membranas mucosas de boca, faringe, esôfago, trato urinário, respiratório e gastrointestinal como um todo. As toxinas produzidas por alguns micro-organismos deste gênero podem ser unicamente responsáveis por sua patogenicidade, não exigindo uma invasão tecidual para tais efeitos negativos no indivíduo. No entanto, algumas características (cepa-específica) como a formação de coágulos de fibrina, por exemplo, são fatores que aumentam a virulência do microorganismo quando este invade o organismo humano ${ }^{[1]}$.

Staphylococcus coagulase positiva (SCoP) são diferentes cepas de micro-organismos do gênero Staphylococcus, dentre eles $S$. aureus, $S$. byicus e $S$. intermedius ${ }^{2]}$, caracterizados pela produção da enzima coagulase a qual é um agente ativo na coagulação capaz de converter fibrinogênio em fibrina, semelhante à ação da protrombina humana ${ }^{[3]}$. O acúmulo de fibrina ao redor das bactérias dificulta a ação fagocítica celular do hospedeiro ${ }^{[1,4]}$. Sabe-se ainda que estas bactérias causam um grande número de infecções graves, principalmente em indivíduos debilitados por doenças crônicas, traumas físicos e imunossupressão, levando à septicemia, endocardite, pneumonia, bacteremia, osteomielite entre outras infecções, tanto em âmbito hospitalar quanto ambulatorial ${ }^{[3,4]}$. A maior incidência de indivíduos com infecção por SCoP são os neonatos e lactantes, assim como os pacientes operados cirurgicamente ${ }^{[4]}$. Além da infecção causada por estes microorganismos, as cepas SCoP são consideradas um risco para a saúde pública pela produção de enterotoxinas $^{[5]}$ que quando presentes em alta quantidade em alimentos, causam intoxicação alimentar, além de alterações de cor, aroma e sabor em alimentos ${ }^{[6]}$. Os principais sintomas da intoxicação por enterotoxinas de SCoP são náuseas, vômito e diarreia ${ }^{[]}$. Ressalta-se ainda que o período de incubação, gravidade e duração da doença são diferentes em função da idade, do estado nutricional, da sensibilidade individual e da quantidade de alimento ingerida ${ }^{[2]}$, o que em crianças, principalmente recém-nascidos (RNs) sob internação hospitalar em UTI neonatal apresenta um risco elevado para fatalidade ${ }^{[7]}$, levando-se em conta que estes usualmente são consumidores de leite provindo de Banco de Leite e possuem baixa resistência às infecções neonatais ${ }^{[8]}$.

Staphylococcus coagulase negativa (SCoN) são comumente encontrados na pele e mucosas dos seres humanos, compondo a flora normal dos mesmos, sendo ainda subdivididos em dois grupos: saprophyticuse não saprophyticus, baseado na sua sensibilidade à nocibiocina. Exemplos de $\mathrm{SCoN}$ são S. epidermidis, S. haemolyticus, S.bominis, S. capitis, S. warneri, S. saprophyticus, S. cobniie S. xylosus. Estas bactérias são consideradas agentes oportunistas, causadores de infecções nosocomiais e comunitárias. Os tipos de infecção frequentemente associadas aos SCoN compreendem: infecções urinárias, associadas a dispositivos permanentes, bacteremias em hospedeiro comprometido, endocardite de válvulas cardíacas naturais e protéticas, osteomielite e endoftalmite pós-cirúrgica ${ }^{[0]}$.

Os SCoN são considerados como importantes causas de infecções, particularmente em ambiente hospitalar, em pacientes com a defesa orgânica comprometida. Esta torna-se um problema clinicamente relevante, devido à resistência aos medicamentos pertencentes ao grupo das penicilinas utilizados para o combate as infecções, onde passam a não desempenhar mais corretamente sua função, tornando o tratamento inviável ${ }^{[9]}$. A septicemia, uma das consequências desta resistência, é uma síndrome clínica caracterizada por sinais sistêmicos de infecção acompanhada pela presença de bacteremia, especialmente em pacientes de UTI. Esta é ainda uma das principais causas de morte em lactentes devido a sua multirresistência e não especifidade na manifestação clínica no RN ${ }^{[10-12]}$.

A presença de micro-organismos SCoP e SCoN no leite humano (LH) pode ser interpretada como contaminação secundária a partir da pele e fossas nasais ou por condições higiênicas insatisfatórias dos utensílios empregados para a manipulação. O leite é um meio ideal para o crescimento dos micro-organismos, devido à sua composição nutricional, alta atividade de água, $\mathrm{pH}$ próximo a neutralidade, dentre outros fatores que resultam em um alimento com baixa barreira ao desenvolvimento destes 
micro-organismos. Assim, a multiplicação destes é muito rápida, se a temperatura for ideal para $\mathrm{o}$ crescimento $^{[11]}$.

As cepas Staphylococcus spp. podem ser facilmente identificadas nas vias aéreas superiores dos homens e pele (principalmente mucosa) o que possibilita uma fácil transmissão para alimentos e utensílios $^{[2,11,13,14,15]}$. Somando-se a isso o gênero Staphylococcus é o mais presente em superfícies de Unidades de Tratamento Intensivo (UTIS) ${ }^{[16]}$. Em ambientes hospitalares, onde é comum a presença de Staphylococcus aureus e cepas S. coagulase negativa ${ }^{[17]}$, os funcionários portadores de cepas patógenas conhecidas devem ser afastados e tratados com antibióticos para erradicação do problema. Muitos portadores desta bactéria são assintomáticos, o que representa um fator de transmissão para leite porcionado em lactário, quando tais manipuladores não são afastados e/ou não seguem padrões de higiene adequados na realização do procedimento ${ }^{[1]}$.

Além do tipo de agente microbiano ser determinante no desenvolvimento da infecção decorrida do mesmo, outros fatores estão envolvidos como a susceptibilidade do doente, a idade, estado imunológico, doença base $\mathrm{e}$ as intervenções diagnósticas e terapêuticas. A infância e a terceira idade estão associadas a uma menor resistência à infecção, assim como portadores de doenças crônicas têm susceptibilidade aumentada às infecções por agentes oportunistas. A desnutrição também é considerada um fator de risco, além de objetos ou substâncias contaminadas que podem entrar em contato com o indivíduo ${ }^{[2,18]}$.

O LH doado por lactantes aos Banco de Leite Humanos (BLH) chega aos hospitais em condições higiênico-sanitárias adequadas para o consumo seguro dos lactentes, pois agentes patogênicos são inativados no processo de pasteurização, como mostra um estudo de Wright e Feeney ${ }^{[19]}$. O BLH pasteuriza o LH de acordo com as normas da Agência Nacional de Vigilância Sanitária (ANVISA), impostas pela RDC no 171 de 4 de setembro de $2006^{[20]}$, ou seja, a $62,5^{\circ} \mathrm{C}$ por 30 minutos, contados a partir do pré-aquecimento. As embalagens em que o LH é depositado são esterilizadas em auto-clave e seu armazenamento ocorre em congeladores com temperatura inferior a $-5^{\circ} \mathrm{C}$. Todos estes processos tem suas variáveis monitoradas constantemente e o LH não sofre manipulação, porcionamento ou contato humano após a pasteurização, o que inviabiliza a transmissão de Staphylococcus spp. antes da chegada ao hospital.

Porém, mesmo levando-se em consideração que o LH pasteurizado no BLH passa por rígido controle de qualidade microbiológico, este está susceptível à contaminação horizontal durante a manipulação em seu porcionamento no lactário dos Hospitais que o recebem.

O objetivo do presente estudo foi de pesquisara incidência de Staphylococcus spp. no LH estocado em lactário de hospital público em Santa Catarina (Brasil), quando do momento de seu porcionamento para distribuição.

\section{MATERIAL E MÉTODOS}

\section{Coleta de amostras}

Foram coletadas 50 amostras, de leite humano pasteurizado, aleatoriamente de julho de 2013 a junho de 2014, em diferentes épocas do ano. A coleta foi realizada pelos profissionais do próprio lactário, no momento do porcionamento do leite humano para ser servido aos lactentes na UTI neonatal do Hospital, com as mesmas seringas estéreis utilizadas para servi-lo. As amostras foram colocadas em eppendorfs estéreis com capacidade de $3 \mathrm{~mL}$. As amostras, $\operatorname{logo}$ após a coleta, foram transportadas para o laboratório de Microbiologia do Campus III da Universidade Regional de Blumenau em caixa isotérmica, em menos de uma hora até o início das análises.

\section{Análise microbiológica}

Cada amostra passou por diluições decimais até $10^{-4}$, com posterior plaqueamento Pour-Plate, em duplicata, emplacas contendo meio Baird-Parker $(\mathrm{BP})\left(\right.$ Himedia $\left.^{\circledR}\right)$ e suspensão estéril de gema de ovo $50 \%(\mathrm{v} / \mathrm{v})$ enriquecida com telurito a $0,1 \%(\mathrm{p} / \mathrm{v})$ $\left(\right.$ Laborclin $\left.^{\circledR}\right)$. Estas foram incubadas a $36 \pm 1^{\circ} \mathrm{C}$ por 48 horas. Após a incubação, as Unidades Formadoras de Colônias (UFC) típicas foram inoculadas em meio caldo Brain Heart Infusion (BHI) $\left(\right.$ Himedia $^{\circledR}$ ) e incubadas durante 24 horas à mesma temperatura. Foram consideradas como típicas todas as UFC's convexas de coloração preta e registrou-se aquelas que tiverem anel branco e halo transparente. Após a incubação em BHI foi confirmado o gênero Staphylococcus spp. pelos testes de Gram, catalase e coagulase. Toda a metodologia seguiu as normas internacionais de análise da APHA ${ }^{[21]}$. 
Os resultados foram considerados, em percentual, como sendo ou não Staphylococcus spp. Para as placas positivas foram registradas as quantidades de UFC's e posteriormente comparadas com a recomendação delimites máximos permitidos de $10^{2} \mathrm{UFC} / \mathrm{mL}$ de micro-organismos aeróbios mesófilos por amostra de LH pasteurizado proveniente de $\mathrm{BLH}$, imposta pela RDC nํㅜ 12, de 02 de janeiro de 2001 da ANVISA ${ }^{[22]}$. Destaca-se que este limite máximo é um parâmetro estipulado para um grupo de micro-organismos, dentro do qual situa-se o gênero Staphylococcus. Também foi registrado a relação entre a amostra com o frasco de origem do leite, para informar tanto o BLH quanto o hospital.

\section{RESULTADOS}

Das 50 amostras de leite humano pasteurizado analisadas, 36\% ( $\mathrm{n}=18)$ apresentaram Staphylococcus spp., confirmados pela coloração de Gram e teste da catalase. Todas estas amostras obtiveram resultado negativo para o teste de coagulase. Das amostras contaminadas $(\mathrm{n}=18)$ constatou-se ainda que $38,8 \%(n=7)$ ultrapassaram os limites máximos permitidos pela legislação nacional $\left(>10^{2} \quad \mathrm{UFC} / \mathrm{mL}\right.$ de micro-organismos aeróbios mesófilos por amostra de $\mathrm{LH}$ pasteurizado proveniente de BLH), conforme previsto pela ANVISA ${ }^{[22]}$ (tabela 1). Ressalta-se que a recomendação feita pela legislação refere-se à contagem total de micro-organismos aeróbios mesófilos, grupo ao qual pertence a bactéria patogênica. Esse dado equivale a $14 \%$ das 50 amostras totais analisadas.

Tabela 1: Número de UFC's encontradas nas amostras positivas para Staphylococcus spp

\begin{tabular}{lc}
\hline Faixa UFC's /mL de amostra & Número de amostras positivas para Staphylococcus spp. \\
\hline $10^{0} \models 10^{1}$ & 0 \\
$10^{1} \mathrm{H} 10^{2}$ & 11 \\
$>10^{2}$ & 7 \\
\hline Total & 18 \\
\hline
\end{tabular}

Fonte: Dados da pesquisa.

\section{DISCUSSÃO}

O nível encontrado de Staphylococcus spp. é significativo, considerando que este leite é oferecido aos RN sem estado crítico de saúde. O resultado agravante obtido neste trabalho que o nível acima de $10^{2} \mathrm{UFC} / \mathrm{mL}$ refere-se à bactéria patogênica e não aos micro-organismos aeróbios mesófilos totais, o que significa que as contagens de micro-organismos aeróbios mesofilos é superior ao limite máximo exigido pela legislação vigente.

A presença dos micro-organismos encontrados em LH é de difícil controle, pois este é um excelente meio de cultura para proliferação bacteriana devido a sua composição e na vigência de temperatura ideal para o crescimento ${ }^{[11]}$. Mesmo assim, sua presença acima dos limites de segurança impostos pela legislação não é aceitável[ ${ }^{[23]}$.
Os achados de Staphylococcus spp. nas amostras analisadas pode ser decorrente da microbiota de pele e mucosas dos manipuladores que oferecem o leite aos RNs. A contaminação das amostras evidencia a necessidade de maior cuidado e controle sanitário por parte dos manipuladores que porcionam e administram o leite aos RNs, visando assim, evitar possíveis infecções neonatais, sepse e morte ${ }^{[23]}$.

A obtenção de leite de boa qualidade garante que não haja casos de infecção providas de contaminação por micro-organismo. Custódio et al. ${ }^{[24]}$ avaliaram em seu estudo a microbiota das mãos dos profissionais de saúde, sendo o principal achado a presença de SCoN resistentes. Destacando que os profissionais envolvidos na assistência hospitalar daquela unidade não realizavam a higienização correta das mãos como prevenção e controle de infecções, visto que não era adotada pelos mesmos a assepsia das mãos rotineiramente. 
Segundo Silva et al. ${ }^{[25]}$, SCoN tem importância fundamental, pois é apontada como o principal agente de infecções relacionadas à assistência de saúde em neonatologia, sendo a principal causa de morbidade e mortalidade em RNs internados em UTIs. A mortalidade por este agente pode atingir $16 \%$, principalmente em RNs de muito baixo peso. A infecção por SCoN é também a maior causa de bacteremia adquirida no ambiente hospitalar, na maioria dos pacientes mantidos em UTIs neonatal. Estes micro-organismos apresentam risco de bacteremia nosocomial em $\mathrm{RN}$ de baixo peso, os quais são imunologicamente imaturos e frequentemente requerem administração de substâncias nutritivas.

Um estudo prospectivo longitudinal de 10 anos realizado na Austrália encontrou $57 \%$ da septicemia de início tardio causada por Staphylococcus spp. coagulase negativo e $0,3 \%$ das mortes foram causadas por estes micro-organismos, sendo estes inclusive os possíveis contribuidores para mais 1,5\% das mortes neonatais registradas ${ }^{[14]}$.

De forma semelhante ao presente estudo, Silveira et al. ${ }^{[23]}$ também constataram a presença de amostras de LH contaminadas por microorganismos SCoN no Hospital das Clínicas (HC) da Universidade Federal do Triângulo Mineiro (UFTM).

Diante dos resultados encontrados por Salles e Goulart ${ }^{[26]}$, ficou evidenciado que os lactários podem constituir uma fonte endógena na disseminação das doenças infecciosas. A avaliação das mãos e região orofaríngea dos manipuladores confirmou contaminação de $S$. aureus. Os autores destacam a necessidade de controle higiênicosanitário, a fim de garantir qualidade no fornecimento de leite e fórmulas infantis, pois não é o leite humano processado termicamente de forma correta que dissemina esta bactéria e sim o manipulador que pode transferi-la tanto no leite quanto nas fórmulas servidas.

\section{CONCLUSÕES}

Levando-se em conta que (I) o gênero Staphylococcus é o mais presente em superfícies de UTIS ${ }^{[16,27] ;}$ (II) que contaminações por cepas Staphylococcus coagulase negativo são frequentes e perigosas para a saúde dos neonatos ${ }^{[28]}$; (III) que estas geram grandes gastos hospitalares em todo o mundo ${ }^{[13]}$; e (IV) os resultados encontrados na presente pesquisa, sugere-se a melhoria das práticas higiênico-sanitárias na manipulação do LH ao ser porcionado em lactário de hospital, visando assim evitar todas as possíveis consequências supracitadas.
A manipulação inadequada do LH mostrou-se um fator significativo de transmissão bacteriana, culminando com os resultados encontrados. Para que tal ocorrência seja evitada devem ser revistas as técnicas de manejo do LH no seu porcionamento, além da verificação da metodologia de controle microbiológico local, para torná-lo mais rígido no serviço de manipulação, buscando reduzir significativamente a incidência de contaminação do LH tão fundamental para saúde daqueles que dele necessitam.

\section{REFERÊNCIAS}

[1] Madigan MT, Martinko JM, Parker J. Brock: Biología de los Microorganismos. 10 ed. Madrid: Prentice Hall; 2003. $1096 \mathrm{p}$.

[2] Franco BDGM, Landgraf M. Microbiologia dos Alimentos. São Paulo: Atheneu; 2008. 182 p.

[3] Santos BHC, Souza EL, Sousa CP, et al. Manipuladores como causas potenciais de contaminação microbiana de alimento enteral. Revista Inf. 2003/2004; 15(11-12): 71-3.

[4] Betancourt OH, Cuesta LYU, Méndez DR, et al. Staphylococcus aureus y su identificación en los laboratorios microbiológicos: revisión bibliográfica. Arc Méd Camagüey. 2005;9(1):[cerca de 11 p.]. Disponível em: <http:/ / www.redalyc.org/articulo.oa?id=211117623016>.

[5] Camacho NN, Marini P, Armas RD, et al. Determinação de Staphylococcus coagulase positiva e de indicadores higiênico-sanitários em amostras de queijo ralado. In: XIII Congresso de Iniciação Científica [Internet]; 27-29 out 2004; Rio Grande do Sul, Brasil. Pelotas: Universidade Federal de Pelotas; [Acesso em: 12 jul 2014]. 4 p. Disponível em: <http://www2.ufpel.edu.br/cic/2004/arquivos/conteudo _CB.html\#00594 >.

[6] Santos WLM Avaliação microbiológica de saladas cruas e cozidas servidas em restaurantes industriais da cidade de Belo Horizonte. Rev Hig Alim. 1997; 11(40):2630.

[7] Clemente MG, Valle RHP, Abreu LR. Staphylococcus em queijos fabricados com leite cru e pasteurizado. Rev Hig Alim. 2003; 17(104/105): 38-9.

[8] Serafini ÁB, André MCDPB, Rodrigues MAV, et al. Qualidade microbiológica de leite humano obtido em banco de leite. Rev. Saúde Pública. 2003; 37(6): 775-9.

[9] Bezerra BA, Araújo CE, Alves LCW, Oliveira AR. Staphylococcus coagulase negativa resistente a oxacilina no Hospital Regional Público de Araguaia - Pará [monografia]. [Manaus]: Faculdade de Ensino Superior da Amazônia Reunida; 2010. 10 p. Disponível em: $<$ http://www.fesar.com.br/Staphylococcus $\% 20$ coagulase. $\operatorname{pdf}>$. 
[10] Tariq MT. Bacteriologic profile and anibiogram of blood culture isolates from a children's hospital in Kabul. J Col Phys Surg Pak. 2014; 24(6): 396-9.

[11] Cunha SRLM, Lopes MAC. Estudo da produção de $\beta$-lactamase e sensibilidade às drogas da linhagem estafilococos coagulase-negativo isolados de recémnascidos. J Bras Pat Med Lab. 2002;38(4): 281-90. Disponível em: <http://dx.doi.org/10.1590/S1676$24442002000400006>$.

[12] Silveira CR, Procianoy R. Uma revisão sobre sepse neonatal. Bol Cient Ped. 2012;1(1):29-35.

[13] Costa SF, Micelia MH, Anaissie EJ. Mucosa or skin as source of coagulase-negative staphylococcal bacteraemia? Lancet Infec Dis. 2004;4(8): 278-86.

[14] Isaacs D. A ten year, multicentre study of coagulase negative staphylococcal infections in Australasian neonatal units. Arch Dis Child Fetal Neonatal. 2003;88(2): F89-F93.

[15] Alcarãs LE, Satorres SE, Sepulveda L, et al. Detección de Staphylococcus aureus spp. en manipuladores de alimentos. Aliment Latinoam. 1997; (219):44-7.

[16] Martins JRTL. Caracterização antimicrobiana de cepas ambientais de Staphylococcus spp. isoladas de uma Unidade de Terapia Intensiva (UTI) neonatal [monografia]. [Paraíba]: Universidade Estadual da Paraíba; 2012. 19 p. Disponível em: $<$ http://dspace.bc.uepb.edu.br/jspui/bitstream/1234567 89/1753/1/PDF\%20-

\%20Jos\%C3\%A9\%20Ricardo \%20Tom\%C3\%A9\%20Lop es\%20Martins.pdf>.

[17] Agência Nacional de Vigilância Sanitária (BR) Boletim Informativo da Rede Nacional de Monitoramento da Resistência Microbiana em Serviços de Saúde - Rede RM. Brasília: ANVISA, [atualizado em 2009 Jul 10; citado em 12 Jul 2014]. Disponível em: <http://www.anvisa.gov.br/divulga/newsletter/rede_rm /2009/100709_perfil_sensibilidade.htm>.

[18] Instituto Nacional de Saúde Dr. Jorge Ricardo. Prevenção de infecções adquiridas no hospital: um guia prático. Lisboa: Ministério da Saúde; 2002. 93 p. Disponível em $<$ http://www.bvsde.paho.org/bvsacd/cd49/man_oms.pd $\mathrm{f}>$.

[19] Wright KC, Feeney AM. The bacteriological screening of donated human milk: laboratory experience of British Paediatric Association's published guidelines. J Infect. 1998,36(2):23-7.

[20] BRASIL. Agência Nacional de Vigilância Sanitária. Dispõe sobre o Regulamento Técnico para o funcionamento de Bancos de Leite Humano. Resolução
RDC no 171, de 4 de setembro de 2006. Diário Oficial da União, Poder Executivo, Brasília (DF); ago 2006.

[21] Salfinger Y, Tortorello ML. Compendium of methods for the microbiological examination of foods. Washington: APHA; 2015. 995 p.

[22] BRASIL. Agência Nacional de Vigilância Sanitária. Aprova o Regulamento Técnico sobre padrões microbiológicos para alimentos. Resolução RDC no 12, de 02 de janeiro de 2001. Diário Oficial da União, Poder executivo, Brasília (DF); jan 2001.

[23] Silveira MAL, D'Amorim GFM, Silva DRV, et al. Controle microbiológico de leite humano de um hospital universitário. Rev Baiana de Saúde Pública. 2012, 36(3): 844-50. Disponível em: $<$ http://inseer.ibict.br/rbsp/index.php/rbsp/article/vie $\mathrm{w} / 560>$.

[24] Custódio J, Alves JF, Silva FM, et al. Avaliação microbiológica das mãos de profissionais da saúde de um hospital particular em Itumbiara, Goiás. Rev Cienc Med PUCCAMP. 2009, 18(1):7-11. Disponível em: $<$ http://periodicos.puc-

campinas.edu.br/seer/index.php/cienciasmedicas/article /view/649>

[25] Silva RHE, Silva G K, Quinalia BR, et al. Banco de leite humano: controle do risco de contaminação pelas doadoras. Rev Funec Cient Nutr. 2013;1(1):[cerca de 9 p.]. Disponível em: $<$ http://seer.funecsantafe.edu.br/index.php?journal=rfen \&page $=$ article $\&$ op $=$ view $\&$ path $\% 5 B \% 5 D=966 \&$ path $\% 5$ $\mathrm{B} \% 5 \mathrm{D}=949>$

[26] Salles KR, Goulart R. Diagnóstico das condições higiênico-sanitárias e microbiológicas de lactários hospitalares. Rev de Saúde Pública. 1997, 31(2):131- 9. Disponível em: <http://dx.doi.org/10.1590/S003489101997000200005>.

[27] D'angio CT, Mcgowan KL, Baumgart S, et al. Surface colonization with coagulase-negative staphylococci in premature neonates. J Pediatr. 1989;114(6):1029-34.

[28] Strunk T, Richmond P, Simmer K, et al. Neonatal immune responses to coagulase-negative staphylococci. Curr Opin Infect Dis. 2007;20(4):370-5.

\section{Agradecimentos}

Ao CNPq pela bolsa de Iniciação Científica; ao Hospital de rede pública, e aos funcionários do respectivo lactário, pela cooperação com a pesquisa; e ao BLH Blumenau, pela parceria durante os trabalhos envolvendo o cuidado materno-infantil. 